\title{
Silagens de girassol e de milho em dietas de vacas leiteiras: consumo e digestibilidade aparente
}

[Sunflower and corn silages in lactating cow diets: intake and digestibility]

\author{
L.A. Leite ${ }^{1}$, B.O. Silva ${ }^{1}$, R.B. Reis ${ }^{2}$, B.N. Faria ${ }^{1}$, L.C. Gonçalves ${ }^{2}$, \\ S.G. Coelho ${ }^{2}$, H.M. Saturnino ${ }^{2}$ \\ ${ }^{1}$ Aluno de pós-graduação - Escola de Veterinária - UFMG \\ ${ }^{2}$ Escola de Veterinária - UFMG \\ Caixa Postal 567 \\ 30123-970 - Belo Horizonte, MG
}

\begin{abstract}
RESUMO
Avaliaram-se o consumo e a digestibilidade aparente de dietas, contendo diferentes proporções de silagem de girassol em substituição à silagem de milho, para vacas leiteiras em lactação. Foram utilizadas cinco vacas da raça Holandesa, que produziam $25 \mathrm{~kg}$ leite $/$ dia, distribuídas em um delineamento em quadrado latino $5 \times 5$. Os tratamentos foram compostos por: $100 \%$ de silagem de girassol e concentrado (100SG), 66\% de silagem de girassol mais 34\% de silagem de milho e concentrado (66SG), $34 \%$ de silagem de girassol mais $66 \%$ de silagem de milho e concentrado (34SG), 100\% de silagem de milho e concentrado (100SM) e 100\% de silagem de milho mais caroço de algodão (16,5\% da matéria seca) e concentrado (SM+CA). A ingestão de matéria seca (17,8kg para $100 \mathrm{SG}$ e $21,6 \mathrm{~kg}$ para $100 \mathrm{SM})$, a ingestão de matéria orgânica $(15,5 \mathrm{~kg}$ para $100 \mathrm{SG}$ e $20,2 \mathrm{~kg}$ para $100 \mathrm{SM})$, a ingestão de fibra insolúvel em detergente neutro $(8,1 \mathrm{~kg}$ para $100 \mathrm{SG}$ e $9,9 \mathrm{~kg}$ para $100 \mathrm{SM})$, a digestibilidade aparente da fibra insolúvel em detergente neutro (30,7\% para $100 \mathrm{SG}$ e $51,4 \%$ para $100 \mathrm{SM})$ e da fibra insolúvel em detergente ácido (28,4\% para $100 \mathrm{SG}$ e $49,4 \%$ para $100 \mathrm{SM})$ foram menores para a dieta $100 \mathrm{SG}$ comparada à dieta $100 \mathrm{SM}$ $(\mathrm{P}<0,05)$. A substituição parcial da silagem de milho pela silagem de girassol pode ser uma alternativa viável na alimentação de vacas leiteiras.
\end{abstract}

Palavras-chave: gado de leite, consumo, digestibilidade, girassol, milho

\begin{abstract}
The intake and the apparent digestibility of dry matter, organic matter, neutral detergent fiber, acid detergent fiber and the intake of crude protein were evaluated in lactating Holstein cows fed sunflower silage (SS) in replacement of corn silage (CS) in their diets. Five ruminal cannulated cows, 60 to 82 days in milk, were arranged in a $5 \times 5$ latin square design. The treatments werethe following: $100 \%$ corn silage (100CS) and concentrate; 34\% sunflower silage plus 66\% corn silage (34SS) and concentrate; $66 \%$ sunflower silage plus 34\% corn silage (66SS) and concentrate; 100\% sunflower silage (100SS) and concentrate; and 100\% corn silage plus whole cotton seed (CS-WCS) and concentrate. Dry matter (17.86kg for $100 S S$ and $21.62 \mathrm{~kg}$ for $100 \mathrm{CS}$ ) and organic matter intake $(17.5 \mathrm{~kg}$ for $100 \mathrm{SS}$ and $20.2 \mathrm{~kg}$ for 100CS), intake and apparent digestibility of neutral detergent fiber and acid detergent fiber were lower for 100SS compared to 100CS $(P<0.05)$. Apparent digestibility of organic matter for treatment 100SS was the lowest (54.8\%). Increasing levels of corn silage in the diets increased the dry matter intake, the organic matter intake and the apparent digestibility. Parcial replacement of the corn silage with sunflower silage could be a viable option for lactating cows diets.
\end{abstract}

Keywords: dairy cattle, digestibility, intake, corn, sunflower

Recebido em 6 de junho de 2005

Aceito em 21 de novembro de 2006

E-mail: leonardoleite@superig.com.br 


\section{INTRODUÇ̃̃̃O}

Vacas leiteiras em lactação necessitam de forragem de boa qualidade na dieta, para a maximização da sua produção, manutenção da saúde e sustentação de um ambiente rumenal estável. Grande variedade de forrageiras pode ser utilizada para o processo de produção de silagem. A silagem de milho é considerada padrão em função do seu valor nutritivo. Entretanto, o alto valor do milho grão para a exportação, para o emprego na alimentação humana e nas rações para monogástricos, tem levado os pecuaristas a buscar, em outras forrageiras, alternativas para a alimentação do rebanho (Almeida et al., 1995).

A silagem de girassol (Helianthus annus) apresenta-se como mais uma alternativa de alimento conservado na forma de silagem (Henrique et al., 1998a; Henrique et al., 1998b; Tomich et al., 2003). Quando comparada à silagem de milho, normalmente observam-se concentrações mais elevadas de proteína bruta (PB) e extrato etéreo (EE) para a silagem de girassol, assim como diferenças na composição da parede celular (Henrique et al., 1998a), conferindo-lhe características particulares. Apesar de ter sido introduzido na época da colonização como oleaginosa, há bem pouco tempo o girassol tem sido estudado e utilizado como planta forrageira alternativa.

Tão importante como a capacidade de produção de uma forrageira é o seu valor para alimentação animal. De maneira geral, as respostas em relação aos parâmetros fisiológicos e ao desempenho produtivo de animais submetidos às dietas baseadas em silagem de girassol são distintas às dos animais alimentados com silagem de milho. Silva et al. (2004) observaram que a produção de leite corrigida para $4 \%$ de gordura (LCG 4\%) não foi influenciada pela substituição total da silagem de milho pela silagem de girassol, como volumoso na dieta de vacas leiteiras em lactação.

Os principais fatores responsáveis pela conversão de forragem em produção animal são: a ingestão de energia, a digestibilidade dessa energia e a eficiência de conversão da energia digestível (Waldo e Jorgensen, 1980). O estudo da digestão parcial dos nutrientes nas dietas de vacas leiteiras permite determinar quantitativamente sua utilização nas diferentes partes do trato gastrintestinal. Além do conhecimento da composição bromatológica do alimento fornecido, aliada à mensuração do consumo de alimentos, é importante o conhecimento da utilização dos nutrientes pelo animal, a qual é obtida por meio do estudo da digestão. Maior consumo e melhor utilização dos nutrientes resultam em maior produtividade animal (Valadares Filho, 1985; Fontes, 1996).

Os coeficientes de digestibilidade fazem referência à fração de um determinado alimento da dieta, que desaparece durante sua passagem através do trato gastrintestinal. Supõe-se, assim, que o processo de absorção também faz parte da determinação do valor nutritivo do alimento consumido. A maior permanência do material ingerido no rúmen também pode apresentar efeito benéfico para sua degradação. A fração não degradável deve deixar o rúmen sem sofrer hidrólise, ou qualquer outra ação microbiana, enquanto a potencialmente degradável pode desaparecer do rúmen tanto por passagem, quanto por degradação (Van Soest, 1994).

Os trabalhos que avaliaram consumo e digestibilidade das dietas de vacas leiteiras alimentadas com a silagem de girassol são escassos (Valdez et al., 1988; Henrique et al., 1998). No Brasil, esses estudos são praticamente inexistentes, apesar do plantio de girassol para ensilagem vir aumentando e ter se tornado prática comum para determinadas épocas do ano em algumas regiões do país.

O objetivo deste estudo foi avaliar o consumo voluntário e a digestibilidade aparente da matéria seca (MS), da matéria orgânica (MO), da fibra insolúvel em detergente neutro (FDN), da fibra insolúvel em detergente ácido (FDA), do extrato etéreo (EE) e do consumo de proteína bruta $(\mathrm{PB})$ de dietas de vacas leiteiras em lactação, na qual a silagem de girassol substituiu total ou parcialmente a silagem de milho.

\section{MATERIAL E MÉTODOS}

Foram utilizadas cinco vacas da raça Holandesa, pluríparas, com peso vivo médio de $550 \mathrm{~kg}$, entre 60 e 82 dias em lactação, com produção média de $25 \mathrm{~kg}$ de leite/dia, alojadas individualmente em instalações tipo tie stall. Os animais foram distribuídos aleatoriamente nos tratamentos, em delineamento de quadrado latino $(5 \times 5)$. Cinco períodos experimentais foram avaliados com duração de 21 dias cada, sendo 14 dias para adaptação e sete para coleta de dados. 


\section{Leite et al.}

Os tratamentos consistiram na substituição parcial ou total da silagem de milho (SM) pela silagem de girassol (SG) na dieta, a saber: $100 \%$ de silagem de girassol mais concentrado (100SG), 66\% de silagem de girassol e $34 \%$ de silagem de milho mais concentrado (66SG), 34\% de silagem de girassol e $66 \%$ de silagem de milho mais concentrado (34SG), $100 \%$ de silagem de milho mais concentrado (100SM) e $100 \%$ de silagem de milho mais caroço de algodão e concentrado $(\mathrm{SM}+\mathrm{CA})$. No tratamento $\mathrm{SM}+\mathrm{CA}$, a inclusão do caroço foi $16,5 \%$ da MS total, fornecendo um produto com maior teor de lipídeo, na tentativa de se igualar com o tratamento $100 \mathrm{SG}$.
As dietas foram balanceadas com valores constantes de proteína visando suprir os requisitos nutricionais dos animais (Tab. 1) de acordo com o Nutrient... (2001). Cinco concentrados foram formulados com farelo de soja, polpa cítrica, milho moído, farelo de algodão, calcário e mistura mineral comercial (Tab. 2). A relação volumoso:concentrado foi mantida constante, 56:44\%, em relação à matéria seca (MS) total da dieta. $\mathrm{Na}$ Tab. 3, mostra-se a composição bromatológica média das silagens de milho e girassol, utilizadas durante o ensaio experimental.

Tabela 1. Composição bromatológica das dietas segundo a proporção de silagem de girassol em substituição à silagem de milho para vacas leiteiras

\begin{tabular}{lccccc}
\hline \multicolumn{1}{c}{$\begin{array}{c}\text { Composição } \\
\text { bromatológica }\end{array}$} & 100SG & 66SG & Dieta* \\
\cline { 2 - 6 } & 36,7 & 36,5 & 37,2 & 100SM & SM+CA \\
\hline MS, \% & 16,5 & 16,8 & 16,1 & 16,1 & 38,2 \\
PB, \%MS & 42,8 & 44,1 & 45,6 & 47,7 & 16,7 \\
FDN, \%MS & 29,9 & 27,5 & 27,8 & 26,5 & 28,2 \\
FDA, \%MS & 7,4 & 5,9 & 4,4 & 2,7 & 6,2 \\
EE, \%MS & &
\end{tabular}

*Dietas com proporções fixas de $44 \%$ de concentrado e $56 \%$ de volumoso na matéria seca. $\mathrm{MS}=$ matéria seca; $\mathrm{PB}=$ proteína bruta; FDN=fibra em detergente neutro; FDA:=fibra em detergente ácido; $\mathrm{EE}=$ extrato etéreo. $100 \mathrm{SG}=$ silagem de girassol como volumoso único; $66 \mathrm{SG}=66 \%$ de silagem de girassol e $34 \%$ de silagem de milho como volumoso total; $34 \mathrm{SG}=34 \%$ de silagem de girassol e $66 \%$ de silagem de milho como volumoso total; $100 \mathrm{SM}=$ silagem de milho como volumoso único; $\mathrm{SM}+\mathrm{CA}=$ silagem de milho como volumoso único e concentrado contendo caroço de algodão.

As dietas foram oferecidas na forma de ração completa, em quantidades suficientes para produzir cerca de $10 \%$ de sobras. Amostras das dietas fornecidas e das sobras, coletadas durante o período de amostragem, foram pré-secas em estufa de ventilação forçada a $65^{\circ} \mathrm{C}$ por 72 horas, moídas em peneira de $1 \mathrm{~mm}$ e utilizadas para determinação dos teores de matéria seca em estufa a $105^{\circ} \mathrm{C}$. A MS das amostras foi obtida por secagem em estufa a $105^{\circ} \mathrm{C}$ durante 5 a 6 horas, até peso constante, enquanto a MO foi obtida por diferença entre a MS e as cinzas, sendo as cinzas obtidas em mufla, à temperatura de 500 a $600^{\circ} \mathrm{C}$ até combustão total. $\mathrm{O}$ nitrogênio $(\mathrm{N})$ total foi determinado pelo método Kejeldahl, segundo AOAC (Official..., 1995), e o valor da PB obtido multiplicando-se pelo fator 6,25. $\mathrm{O}$ EE foi determinado em aparelho do tipo Goldfish, conforme técnica citada por Silva (1990). Os componentes da parede celular foram obtidos pelo método seqüencial (Van Soest et al., 1991). As amostras das fezes foram processadas da mesma forma que a dieta oferecida, utilizando-se os valores obtidos de MS, MO, FDN, FDA e EE para o cálculo da digestibilidade aparente.
Para a determinação da produção fecal e dos coeficientes de digestibilidade aparente da MS, MO, FDN, FDA, EE dos alimentos, foi utilizada a coleta total de fezes nos $19^{\circ}, 20^{\circ}$ e $21^{\circ}$ dias de cada período experimental. As fezes foram coletadas diretamente do piso do tie stall, armazenadas em coletores de plástico e posteriormente pesadas. $\mathrm{O}$ cálculo da digestibilidade aparente foi feito segundo Church (1988).

Os dados foram analisados pelo procedimento dos modelos fixos (Proc GLM) do pacote estatístico SAS (FREUND et al., 1986). O teste StudentNewman-Keuls foi empregado para comparação entre tratamentos, sendo as diferenças consideradas significativas em $\mathrm{P}<0,05$.

O modelo adotado foi:

$\mathrm{Y}_{\mathrm{ijk}}=\mu+\mathrm{A}_{\mathrm{i}}+\mathrm{P}_{\mathrm{j}}+\mathrm{T}_{\mathrm{k}}+\varepsilon_{\mathrm{ijk}}$, em que

$\mathrm{Y}_{\mathrm{ijk}}=$ resposta do animal $\mathrm{i}$, no período $\mathrm{j}$, sob o tratamento $\mathrm{k}$;

$\mu=$ média geral

$\mathrm{A}_{\mathrm{i}}=$ efeito do animal $\mathrm{i} ; \mathrm{i}=1,2,3,4,5$;

$\mathrm{P}_{\mathrm{j}}=$ efeito do período $\mathrm{j} ; \mathrm{j}=1,2,3,4,5$;

$\mathrm{T}_{\mathrm{k}}=$ efeito do tratamento $\mathrm{k} ; \mathrm{k}=1,2,3,4,5$;

$\varepsilon_{\mathrm{ijk}}=$ erro aleatório. 
Tabela 2. Composição dos ingredientes e análise bromatológica dos concentrados utilizados em dietas contendo diferentes proporções de silagem de girassol em substituição à silagem de milho

\begin{tabular}{lccccc}
\hline & \multicolumn{5}{c}{ Concentrado* } \\
\cline { 2 - 5 } & $\mathrm{C} 1$ & $\mathrm{C} 2$ & $\mathrm{C} 3$ & $\mathrm{C} 4$ & $\mathrm{C} 5$ \\
\hline Ingrediente (\%) & 28,0 & 30,5 & 33,0 & 35,5 & 22,1 \\
Farelo de soja & 21,2 & 18,7 & 16,2 & 13,7 & 13,0 \\
Farelo de algodão & 1,2 & 1,2 & 1,2 & 1,2 & 1,2 \\
Uréia & 8,9 & 8,9 & 11,4 & 16,4 & 2,6 \\
Milho grão moído & 37,5 & 37,5 & 35,0 & 30,0 & 19,7 \\
Polpa cítrica & - & - & - & - & 37,5 \\
Caroço de algodão & 1,3 & 1,3 & 1,3 & 1,3 & 1,3 \\
Bicarbonato de sódio & 1,2 & 1,2 & 1,2 & 1,2 & 1,2 \\
Mineral & 0,6 & 0,6 & 0,6 & 0,6 & 0,6 \\
Sal comum & - & - & - & - & 0,6 \\
Calcário calcítico & & & & & 87,0 \\
Composição bromatológica & 90,0 & 89,6 & 89,0 & 90,1 & 37,3 \\
MS, \% & 30,1 & 32,0 & 33,3 & 30,7 & 19,0 \\
PB, \%MS & 18,4 & 22,2 & 19,2 & 20,8 & 13,6 \\
FDN, \%MS & 13,2 & 14,1 & 14,4 & 14,5 & 2,1 \\
FDA, \%MS & 3,1 & 2,9 & 3,2 & 3,2 & \\
EE, \%MS & & & & \\
\hline
\end{tabular}

* $\mathrm{C} 1=$ concentrado no tratamento com silagem de girassol como volumoso único da dieta; $\mathrm{C} 2=$ concentrado no tratamento com $66 \%$ de silagem de girassol e $34 \%$ de silagem de milho como volumoso total da dieta; $\mathrm{C} 3=$ concentrado no tratamento com $34 \%$ de silagem de girassol e $66 \%$ de silagem de milho como volumoso total da dieta; $\mathrm{C} 4=$ concentrado no tratamento com silagem de milho como volumoso único da dieta; C5=concentrado no tratamento com silagem de milho como volumoso único, concentrado e caroço de algodão. $\mathrm{MS}=$ matéria seca; $\mathrm{PB}=$ =proteína bruta; $\mathrm{FDN}=$ fibra em detergente neutro; FDA=fibra em detergente ácido; $\mathrm{EE}=$ extrato etéreo.

Tabela 3. Composição bromatológica das silagens de milho (SM) e girassol (SG)

\begin{tabular}{|c|c|c|}
\hline $\begin{array}{c}\text { Composição bromatológica } \\
(\% \mathrm{MS})\end{array}$ & $\mathrm{SM}$ & SG \\
\hline $\mathrm{MS}$ & 30,0 & 27,2 \\
\hline PB & 6,9 & 8,8 \\
\hline FDN & 56,9 & 49,3 \\
\hline FDA & 33,2 & 37,3 \\
\hline $\mathrm{EE}$ & 3,8 & 12,6 \\
\hline $\mathrm{Ca}$ & 0,18 & 1,22 \\
\hline $\mathrm{P}$ & 0,16 & 0,10 \\
\hline $\mathrm{pH}$ & 3,97 & 4,56 \\
\hline $\mathrm{N}-\mathrm{NH}_{3} / \mathrm{NT}$ & 6,05 & 16,86 \\
\hline
\end{tabular}

$\mathrm{MS}=$ matéria seca; $\mathrm{PB}=$ proteína bruta; $\mathrm{FDN}=$ porcentagem de fibra insolúvel em detergente neutro; FDA=fibra insolúvel em detergente ácido; $\mathrm{EE}=$ extrato etéreo; $\mathrm{Ca}=$ Cálcio; $\mathrm{P}=$ Fósforo; $\mathrm{N}-\mathrm{NH}_{3} / \mathrm{NT}=$ nitrogênio amoniacal.

\section{RESULTADOS E DISCUSSÃO}

A substituição total da silagem de milho pela silagem de girassol na dieta causou redução significativa $(\mathrm{P}<0,01)$ no consumo de matéria seca (CMS) e as substituições totais ou parciais (100SG e $66 \mathrm{SG} \%$ ) resultaram em redução no consumo de matéria orgânica (CMO) $(\mathrm{P}<0,01 ; \mathrm{Tab} .4)$. A substituição parcial da silagem de milho pela silagem de girassol (34SG) não afetou o CMS, quando comparada ao tratamento 100SM. Quanto ao consumo de nutrientes digestíveis totais (CNDT), somente o tratamento $100 \mathrm{SG}$ apresentou valores diferentes e mais baixos que os demais tratamentos. O CNDT (Tab. 4) e a digestibilidade aparente da matéria orgânica (DAMO) (Tab. 5) apresentaram respostas semelhantes entre os tratamentos. Não foi observada diferença entre os tratamentos utilizados, em relação ao consumo de proteína bruta $(\mathrm{CPB})$, apesar das diferenças no CMS. 


\section{Leite et al.}

Tabela 4. Consumo de matéria seca (CMS) e matéria orgânica (CMO), nutrientes digestíveis totais (CNDT), fibra insolúvel em detergente neutro (CFDN) e fibra insolúvel em detergente ácido (CFDA), carboidratos totais (CCHOt) e carboidratos não fibrosos (CCNF), extrato etéreo (CEE) e proteína bruta (CPB)

\begin{tabular}{lccccccc}
\hline \multirow{2}{*}{ Consumo (kg/dia) } & \multicolumn{7}{c}{ Dietas* } \\
\cline { 2 - 8 } & $100 \mathrm{SG}$ & $66 \mathrm{SG}$ & 34SG & $100 \mathrm{SM}$ & SM+CA & \multicolumn{1}{c}{$\mathrm{P}$} & EPM \\
\hline CMS & $17,86 \mathrm{~b}$ & $19,76 \mathrm{ab}$ & $21,36 \mathrm{a}$ & $21,62 \mathrm{a}$ & $19,76 \mathrm{ab}$ & $<0,01$ & 0,54 \\
CMO & $15,58 \mathrm{~b}$ & $16,40 \mathrm{~b}$ & $19,46 \mathrm{a}$ & $20,28 \mathrm{a}$ & $18,24 \mathrm{ab}$ & $<0,01$ & 0,75 \\
CNDT & $10,82 \mathrm{~b}$ & $13,78 \mathrm{a}$ & $13,10 \mathrm{a}$ & $14,74 \mathrm{a}$ & $13,86 \mathrm{a}$ & 0,01 & 0,68 \\
CFDN & $8,18 \mathrm{~b}$ & $9,20 \mathrm{ab}$ & $8,78 \mathrm{ab}$ & $9,92 \mathrm{a}$ & $10,02 \mathrm{a}$ & 0,02 & 0,37 \\
CFDA & 5,14 & 5,08 & 6,38 & 5,62 & 5,36 & 0,16 & 0,37 \\
CCHOt & $12,14 \mathrm{c}$ & $14,07 \mathrm{~b}$ & $15,55 \mathrm{ab}$ & $16,52 \mathrm{a}$ & $14,38 \mathrm{~b}$ & $<0,01$ & 0,44 \\
CCNF & $4,70 \mathrm{c}$ & $5,56 \mathrm{abc}$ & $6,01 \mathrm{ab}$ & $6,38 \mathrm{a}$ & $5,15 \mathrm{bc}$ & $<0,01$ & 0,23 \\
CEE & $1,36 \mathrm{a}$ & $1,18 \mathrm{a}$ & $0,96 \mathrm{~b}$ & $0,64 \mathrm{c}$ & $1,24 \mathrm{a}$ & $<0,01$ & 0,05 \\
CPB & 3,02 & 3,34 & 3,46 & 3,54 & 3,4 & 0,2 & 0,16 \\
\hline
\end{tabular}

Valores com diferentes letras na mesma linha diferem entre si $(\mathrm{P}<0,05)$.

*Dietas com proporções fixas de $44 \%$ de concentrado e $56 \%$ de volumoso na matéria seca.

$100 \mathrm{SG}=$ silagem de girassol como volumoso único; $66 \mathrm{SG}=66 \%$ de silagem de girassol e $34 \%$ de silagem de milho como volumoso total; $34 \mathrm{SG}=34 \%$ de silagem de girassol e $66 \%$ de silagem de milho como volumoso total; $100 \mathrm{SM}=$ silagem de milho como volumoso único; $\mathrm{SM}+\mathrm{CA}=$ silagem de milho como volumoso único e concentrado contendo caroço de algodão. $\mathrm{P}=$ Probabilidade. EPM=erro-padrão da média.

Tabela 5. Digestibilidade aparente da matéria seca (DAMS), da matéria orgânica (DAMO), da fibra insolúvel em detergente neutro (DAFNA), da fibra insolúvel em detergente ácido (DAFDA) e do extrato etéreo (DAEE)

\begin{tabular}{|c|c|c|c|c|c|c|c|}
\hline \multirow{2}{*}{ Digestibilidade Aparente (\%) } & \multicolumn{7}{|c|}{ Dietas* } \\
\hline & $100 \mathrm{SG}$ & $66 \mathrm{SG}$ & $34 \mathrm{SG}$ & 100SM & $\mathrm{SM}+\mathrm{CA}$ & $\mathrm{P}$ & EPM \\
\hline DAMS & $54,84 \mathrm{~b}$ & $61,52 \mathrm{ab}$ & $62,42 \mathrm{ab}$ & $66,18 \mathrm{a}$ & $63,36 \mathrm{ab}$ & 0,03 & 2,21 \\
\hline DAMO & $54,58 b$ & $62,06 \mathrm{a}$ & $62,98 \mathrm{a}$ & $67,84 \mathrm{a}$ & $63,88 \mathrm{a}$ & 0,01 & 2,15 \\
\hline DAFDN & $30,72 b$ & $42,18 \mathrm{ab}$ & $42,32 \mathrm{ab}$ & $51,44 \mathrm{a}$ & $44,60 \mathrm{a}$ & $<0,01$ & 3,20 \\
\hline DAFDA & $28,44 b$ & $35,26 a b$ & $43,08 \mathrm{ab}$ & $49,44 a$ & $41,00 \mathrm{ab}$ & 0,02 & 3,96 \\
\hline DAEE & $83,80 \mathrm{a}$ & $84,08 \mathrm{a}$ & $83,38 \mathrm{a}$ & $78,44 \mathrm{~b}$ & $88,20 \mathrm{a}$ & $<0,01$ & 1,18 \\
\hline
\end{tabular}

Valores com diferentes letras na mesma linha diferem entre si $(\mathrm{P} \leq 0,05)$.

*Dietas com proporções fixas de $44 \%$ de concentrado e $56 \%$ de volumoso na matéria seca.

$100 \mathrm{SG}=$ silagem de girassol como volumoso único; $66 \mathrm{SG}=66 \%$ de silagem de girassol e $34 \%$ de silagem de milho como volumoso total; $34 \mathrm{SG}=34 \%$ de silagem de girassol e $66 \%$ de silagem de milho como volumoso total; $100 \mathrm{SM}=$ silagem de milho como volumoso único; $\mathrm{SM}+\mathrm{CA}=$ silagem de milho como volumoso único e concentrado contendo caroço de algodão. $\mathrm{P}=$ Probabilidade. $\mathrm{EPM}=$ erro-padrão da média.

O menor consumo de MS do tratamento $100 \mathrm{SG}$ pode explicar o menor consumo de NDT, uma vez que os teores de carboidratos totais e não fibrosos dessa dieta também apresentaram valores inferiores aos demais. No presente trabalho, não se pode especular a inter-relação entre o consumo de energia, representado aqui pelo CNDT, e o consumo de matéria seca. A extensão do controle do CMS pela capacidade de distensão do retículo rúmen (RR) é relacionada com o requisito energético do animal, pelo efeito de enchimento da dieta consumida e pela digestibilidade da dieta.

A literatura não é conclusiva sobre a CMS em dietas contendo silagem de girassol como única fonte de volumoso para vacas leiteiras. Valdez et al. (1988) não observaram diferenças significativas para CMS entre os animais alimentados com SG e SM. Esses autores, ao utilizarem vacas holandesas, com média de 50 dias de lactação e alimentadas com uma variedade de girassol para produção de óleo, observaram redução na digestibilidade da matéria seca (DAMS). A DAMS do tratamento 100SM foi mais alta que a do tratamento $100 \mathrm{SG}$ $(\mathrm{P}=0,03)$, mas ambas não foram diferentes das DAMS dos tratamentos 34SG, 66SG e SM+CA, que também foram semelhantes entre si. A DAMS foi influenciada negativamente somente pela substituição total da silagem de milho pela silagem de girassol como volumoso na dieta. 
O aumento da proporção de SG nas dietas com volumosos mistos, assim como a presença do caroço de algodão, não influenciou a DAMO, entretanto, a completa substituição da SM pela $\mathrm{SG}$ foi prejudicial $(\mathrm{P}=0,01)$.

Berto et al. (1998) e Tomich et al. (2003) observaram que a menor concentração da FDN da $\mathrm{SG}$ em relação à $\mathrm{SM}$ poderia ser uma vantagem para o seu consumo, mas a sua qualidade, demonstrada no presente experimento pela menor digestibilidade aparente da fibra insolúvel em detergente neutro (DAFDN, 30,7\%) e da fibra insolúvel em detergente ácido (DAFDA, 28,4\%), aliada a sua maior concentração de extrato etéreo, estaria comprometendo sua ingestão, em comparação à SM.

Observa-se aumento do consumo de extrato etéreo (CEE) entre os tratamentos, segundo o aumento da concentração de silagem de girassol como volumoso ou caroço de algodão, utilizados como fontes de lipídeo. Os tratamentos 100SG, 66SG e SM+CA apresentaram CEE semelhantes, porém superiores aos tratamentos 34SG e 100SM $(\mathrm{P}<0,01)$. Os animais no tratamento 100SM consumiram $47 \%$ menos extrato etéreo em relação aos animais do tratamento $100 \mathrm{SG}$. Podese observar pelos dados da Tab. 4 que, embora o tratamento 100SG tenha apresentado menor $\mathrm{CMS}$, isso não refletiu no menor $\mathrm{CEE}$, como ocorreu com o consumo de FDA (CFDA).

Embora os CEE dos tratamentos 100SG e SM+CA tenham sido iguais, a DAMS do tratamento $\mathrm{SM}+\mathrm{CA}$ foi aproximadamente $8 \%$ maior, demonstrando que uma possível associação de fatores, como a qualidade da fração fibrosa e o teor de lipídeos, poderiam estar influenciando os consumos e as digestibilidades dos nutrientes.

Conrad et al. (1964) relataram que em dietas com digestibilidades superiores a $66 \%$, o consumo de MS seria controlado por fatores fisiológicos. Forbes (1995) observou que em dietas com digestibilidades inferiores a $66,7 \%$, o consumo de MS seria limitado pelo efeito físico da dieta, relatando que esse limite poderia ser menor ou maior, segundo a demanda energética do animal. Segundo essa informação, o CMS no presente estudo poderia estar mais relacionado aos fatores físicos de controle do consumo. Conclui-se que a capacidade volumétrica do RR dos animais testados poderia estar sendo influenciada pela maior permanência de um material de menor digestibilidade, como a SG, constituinte principal (como volumoso) no tratamento 100SG.

\section{CONCLUSÕES}

Os valores de consumo e digestibilidade, observados neste estudo, indicam que a silagem de girassol pode ser utilizada como volumoso único ou em associação à silagem de milho, na dieta de vacas leiteiras em lactação.

\section{REFERÊNCIAS BIBLIOGRÁFICAS}

ALMEIDA, M.F.; VON TIESENHAUSEN, I.M.E.V.; AQUINO, L.H. et al. Composição química e consumo voluntário das silagens de sorgo, em dois estádios de corte, girassol e milho para ruminantes. Cienc. Prat., v.19, p.315-321, 1995.

BERTO, J.L.; MUHLBACH, P. R. F.; SANTOS, A. C. Qualidade da silagem de milho em unidades de produção de leite no Rio Grande do Sul. In: REUNIÃO ANUAL DA SOCIEDADE BRASILEIRA DE ZOOTECNIA, 35., 1998, Botucatu. Anais... Botucatu: SBZ, 1998.

CHURCH, D. C. El rumiante: fisiologia digestiva y nutrición. Englewood Cliffs: Prentice- Hall, 1988. 650p.

CONRAD, H. R.; PRATT, A. D.; HIBBS, J. W. Regulation of feed intake in dairy cows. 1. Changes in the importance of physical and physiological factors with increasing digestibility. J. Dairy Sci., v.47, p.54-62, 1964.

FONTES, C. A.A., Avaliação de indicadores na determinação da digestibilidade em novilhos. Rev. Soc. Bras. Zootec., v.25, p.529-539, 1996.

FORBES, J. M. Voluntary food intake and diet selection in farm animals. Oxon, UK; CAB International, 1995.

FREUND, R. J.; LITTLE, R.C.; SPECTOR, P. C. SAS system for mixed models. Cary: SAS Institute, 1986. 206p.

HENRIQUE, W.; ANDRADE, J. B.; SAMPAIO, A. A. M. Silagem de milho, sorgo, girassol e suas consorciações. II. Composição bromatológica. In: REUNIÃO ANUAL DA SOCIEDADE BRASILEIRA DE ZOOTECNIA, 
35., 1988, Botucatu. Anais... Botucatu: SBZ, 1998a. p.379-381.

HENRIQUE, W.; ANDRADE, J. B.; SAMPAIO, A. A. M. Silagem de milho, sorgo, girassol e suas consorciações. III. Coeficientes de digestibilidade. In: REUNIÃO ANUAL DA SOCIEDADE BRASILEIRA DE ZOOTECNIA, 35., 1988, Botucatu. Anais... Botucatu: SBZ, 1998b, p.382-384.

NUTRIENT requirement of dairy cattle. 7.ed. Washington: National Academy, 2001. 381p.

NUSSIO, L.G. Cultura de milho para produção de silagem de alto valor alimentício. In:

SILVA, B. O.; LEITE, L. A.; FERREIRA, M. I. C.; et al. Silagens de girassol e de milho em dietas de vacas leiteiras: produção e composição do leite. Arq. Bras. Med. Vet. Zootec., v.56, p.750-756, 2004.

SIMPÓSIO SOBRE NUTRIÇÃO DE BOVINOS, 4., 1991, Piracicaba. Anais... Piracicaba: FEALQ, 1991. p.59-168.

OFFICIAL methodos of analysis of AOAC International. 16.ed. Arlington: AOAC International, 1995. v.1.

SILVA, D. J. Análise de alimentos (métodos químicos e biológicos). Viçosa, MG: UFV, 1990. $166 \mathrm{p}$.

TOMICH, T.R.; RODRIGUES, J.A.S.; GONÇALVES, L. C. et al. Potencial forrageiro de cultivares de girassol produzidos na safrinha para ensilagem. Arq. Bras. Med. Vet. Zootec., v.55, p.756-762, 2003.

VALADARES FILHO, S. C. Digestão total e parcial da matéria seca e carboidratos em bovinos e bubalinos. 1985. 148f. Tese (Doutorado em Zootecnia) - Universidade Federal de Viçosa, Viçosa, MG.

VALDEZ, F.R.; HARRISON, J.H.; FRASEN, S.C. Effect of feeding sunflower silage on milk production, milk composition, and rumen fermentation of lactating dairy cows. J. Dairy Sci., v.71, p.2462-2469, 1988.

VAN SOEST, P.J.; ROBERTSON, J.B.; LEWIS, B.A. Methods for dietary fiber, neutral detergent, and nonstarch polysaccharides in relation to animal nutrition. J. Dairy Sci., v.74, p.35833597, 1991.

VAN SOEST. P. J. Nutricional ecology of the ruminant. 2.ed. Ithaca: Cornell University, 1994. 476p.

YANG, Y.T.; ROHDE, J.M.; BALDWIN, R.L. Dietary lipid metabolism in lactating dairy cows. J. Dairy Sci., v.61, p.1400-1406, 1978.

WALDO, D. R.; JORGENSEN, N. A. Forages for high animal production: nutritional factors and effects of conservation. J. Dairy Sci., v.64, p.1207-1229, 1980. 